\title{
CARACTERIZAÇÃO ESPACIAL DA PULVERIZAÇÃO PNEUMÁTICA NO INTERIOR DO DOSSEL DO CAFEEIRO CONILON
}

\author{
Luciano Canal ${ }^{1}$ \\ Edney Leandro da Vitória ${ }^{2}$ \\ Dannielle Lopes Real ${ }^{3}$ \\ Tatiana Fiorotti Rodrigues ${ }^{4}$ \\ Carla da Penha Simon ${ }^{5}$ \\ Déborah Hoffmam Crause ${ }^{6}$
}

\begin{abstract}
Resumo: A pulverização pneumática tem sido empregada com sucesso nas culturas de café com plantios de alta densidade foliar. Nesse processo, é comum que grande parte das gotas da aplicação de fitossanitários não atinja o interior do dossel, prejudicando a uniformidade de distribuição das gotas, podendo resultar em baixa eficácia de controle. Objetivou-se avaliar, por técnicas de geoestatística, a deposição e distribuição de gotas da pulverização pneumática realizada por equipamento tipo canhão na copa de cafeeiros da variedade Conilon. O experimento foi realizado em uma propriedade rural, em Nova Venécia-ES. A coleta de dados foi realizada por meio da montagem de seis malhas amostrais de 2,20x 2,20 m (4,84 m2), inseridas no meio da copa das plantas selecionadas, exatamente na linha de plantio, em duas plantas consecutivas de cada linha. Os dados experimentais foram submetidos à análise de dependência espacial pela técnica geoestatística, com o programa computacional GS+ Versão 7®. Todas as variáveis analisadas apresentaram estrutura de dependência espacial. A pulverização através do uso de canhões atomizadores pode ser analisada através da geoestatística.
\end{abstract}

Palavras-chave: Geoestatística; Variabilidade espacial; Distribuição de gotas.

\footnotetext{
${ }^{1}$ Agronomia/Universidade Federal do Espírito Santo, Campus São Mateus, Brasil. E-mail: contatcanalluc@hotmail.com.

2 Professor Titular da Universidade Federal do Espírito Santo, Campus São Mateus, Brasil. E-mail: vitoria.edney@gmail.com.

3 Agronomia/Universidade Federal do Espírito Santo, Campus São Mateus, Brasil. E-mail: dannielle.lopes.real@gmail.com.

4 Agronomia/Universidade Federal do Espírito Santo, Campus São Mateus, Brasil. E-mail: tati_fiorotti@hotmail.com.

5 Agronomia/Universidade Federal do Espírito Santo, Campus São Mateus, Brasil. E-mail: carlasimon2009@hotmail.com.

6 Agronomia/Universidade Federal do Espírito Santo, Campus São Mateus, Brasil. E-mail: deborahlife2014@hotmail.com.
} 